\title{
Manajemen Ekspektatif pada Kehamilan Preterm Gemeli Satu Hidup Satu Meninggal
}

\author{
Rimbun Wahyu Gumilar, Yusrawati \\ Fetomaternal Subdivision, Departement of Obstetrics and Gynecology, Medical Faculty of \\ Andalas University, Dr. M. Djamil Central General Hospital Padang \\ Korespondensi: Rimbun Wahyu Gumilar, Email: rimbunwahyugumilar@gmail.com
}

\begin{abstract}
Abstrak
Latar Belakang: Sindrom transfusi janin kembar/twin to twin transfusion syndrome (TTTS) merupakan komplikasi dari kehamilan multipel monokorion (15\%-20\%) dengan risiko morbiditas dan mortalitas tinggi.

Tujuan: Melaporkan kasus TTTS.

Rancangan dan Metode: Merupakan laporan kasus seorang wanita berusia 30 tahun yang dirawat di bangsal obstetri dan ginekologi RSUP Dr. M. Djamil Padang periode 9-13 November 2018 dengan diagnosis awal $\mathrm{G}_{2} \mathrm{P}_{1} \mathrm{~A}_{0} \mathrm{H}_{1}$ gravid preterm 27-28 minggu dengan TTTS.

Hasil: Diagnosis TTTS ditegakkan berdasarkan temuan ultrasonografi; kehamilan monochorionic diamniotic (MCDA) dan polihidramnion pada salah satu kantung (single deepest pocket: 22,64 cm). Dilakukan amnioreduksi dua kali atas indikasi subyektif (sesak); pasien dipulangkan 1 hari kemudian. Pada kontrol pertama (7 hari setelah pasien dipulangkan), salah satu janin diketahui mengalami intrauterine fetal death(IUFD). Kehamilan dipertahankan hingga aterm dengan pemantauan kadar fibrinogen pasien. Kehamilan diterminasi pada usia kehamilan 37 - 38 minggu secara section caesarea transperitoneal (SCTP) atas indikasi letak lintang. Bayi pertama berjenis kelamin perempuan, berat 1.800 gram, panjang badan $41 \mathrm{~cm}$, appearance, pulse, grimace, activity, respiration (APGAR) score 7/8. Bayi kedua berjenis kelamin perempuan, berat 500 gram, panjang badan $35 \mathrm{~cm}$, derajat maserasi grade III. Penyebab intrauterine growth restriction (IUGR) dan IUFD pada kasus ini diduga karena TTTS.

Simpulan: Diperlukan pemantauan kadar fibrinogen hingga kehamilan aterm pada TTTS. Bayi yang lahir hidup memerlukan pemeriksaan lanjutan untuk memantau komplikasi TTTS.
\end{abstract}

Kata kunci: monochorionic diamniotic, sindrom tranfusi janin kembar, ultrasonografi

\section{Expectation Management of Single Fetal Life in Preterm Twin Pregnancy}

\begin{abstract}
Background: Twin to twin transfusion syndrome (TTTS) syndrome is a complication of multiple monocorionic pregnancies (15\% - 20\%) with a high risk of morbidity and mortality.

Objectives: To report a case of TTTS.

Design and Methods: $A$ case report of a woman, 30 years old, was diagnosed as $G_{2} P_{1} A_{0} L_{1}$ preterm pregnancy 27 - 28 weeks with TTTS. Patient was treated in obstetrics and gynecology ward of Central Public Hospital Dr. M. Djamil Padang since November $9^{\text {th }} 2018$ until December $13^{\text {rd }} 2018$.

Results: Twin to twin transfusion syndrome was diagnosed by ultrasound findings; the presence of a monochorionic diamniotic (MCDA) pregnancy and the presence of polyhydramnios in the other sac (single deepest pocket: 22.64 $\mathrm{cm}$ ). Amnioreduction was performed twice for patient's subjective indication (dyspnea); Patient was discharged one day after second amnioreduction. At first control (7 days after discharged), one of fetal twins was known to intrauterine fetal death (IUFD). Pregnancy was maintained till term by monitoring fibrinogen level. The patient was terminated in pregnancy 37 - 38 weeks by section caesarea transperitoneal (SCTP) for indications of transverse lie position. First baby is female, weight $1.800 \mathrm{gr}$, length: $41 \mathrm{~cm}$, appearance, pulse, grimace, activity, respiration (APGAR) score 7/8. Second baby is female, weight $500 \mathrm{gr}$, length $35 \mathrm{~cm}$, maceration level grade III. Twin to twin transfusion syndrome was suspected as cause of intrauterine growth restriction (IUGR) and IUFD in this case.

Conclusion: Monitoring of fibrinogen levels is required until aterm pregnancy in TTTS. Live born baby needs a follow up examination to monitor complications of TTTS.
\end{abstract}

Keywords: monochorionic diamniotic, twin to twin transfusion syndrome, ultrasonography 


\section{Pendahuluan}

Twin to twin transfusion syndrome (TTTS) merupakan suatu komplikasi kehamilan multipel monokorion yang berisiko tinggi menyebabkan kematian fetal/neonatus, terutama pada janin dengan usia kehamilan belum viable dan apabila janin berhasil hidup maka janin tersebut memiliki risiko mengalami gangguan jantung, saraf, dan mental. ${ }^{1-4}$ Twin to twin transfusion syndrome dapat didiagnosis sebelum kelahiran dengan menggunakan ultrasonografi dan harus memenuhi dua kriteria yaitu adanya kehamilan kembar monochorionic diamniotic (MCDA) dan adanya oligohidramnion pada satu kantung gestasi dan polihidramnion pada kantung lainnya. Peningkatan morbiditas dan mortalitas pada MCDA disebabkan oleh anastomosis vaskular yang berakhir pada TTTS. Diperlukan manajemen yang tepat untuk mengurangi morbiditas dan mortalitas. ${ }^{5,6}$

\section{Rancangan Dan Metode}

Sebuah laporan kasus seorang wanita berusia 30 tahun, diagnosis awal dengan $\mathrm{G}_{2} \mathrm{P}_{1} \mathrm{~A}_{0} \mathrm{H}_{1}$ gravid preterm 27 - 28 minggu dengan TTTS. Pasien dirawat di bangsal obstetri dan ginekologi RSUP Dr. M. Djamil Padang periode 9 - 13 November 2018 dan mendapatkan intervensi amnioreduksi. Diagnosis TTTS ditegakkan berdasarkan temuan ultrasonografi (USG).

\section{Laporan Kasus}

Seorang pasien wanita berusia 30 tahun, dengan diagnosis awal $\mathrm{G}_{2} \mathrm{P}_{1} \mathrm{~A}_{0} \mathrm{H}_{1}$ gravid preterm 27 - 28 minggu dengan TTTS. Pada pemeriksaan USG ditemukan janin hidup gemeli intra uteri, letak lintang, aktivitas gerak janin baik, biometri janin 1; biparietal diameter (BPD): $7,09 \mathrm{~cm}$, abdominal circumferencial (AC): $24,42 \mathrm{~cm}$, estimated fetal weight (EFW): 1.301 gram, fetal heart rate (FHR): 142x/menit dan biometri janin II; biparietal diameter (BPD): $7,02 \mathrm{~cm}$, abdominal circumferencial (AC): 23,96 cm, estimated fetal weight (EFW): 1.238 gram, fetal heart rate (FHR): $152 \mathrm{x} /$ menit, single deepest pocket (SDP): 22,64 cm; plasenta tertanam di korpus posterior maturase grade 2. Pemeriksaan USG tersebut memberikan kesan gravid 28 - 29 minggu sesuai biometri dengan TTTS + letak lintang + polihidramnion.

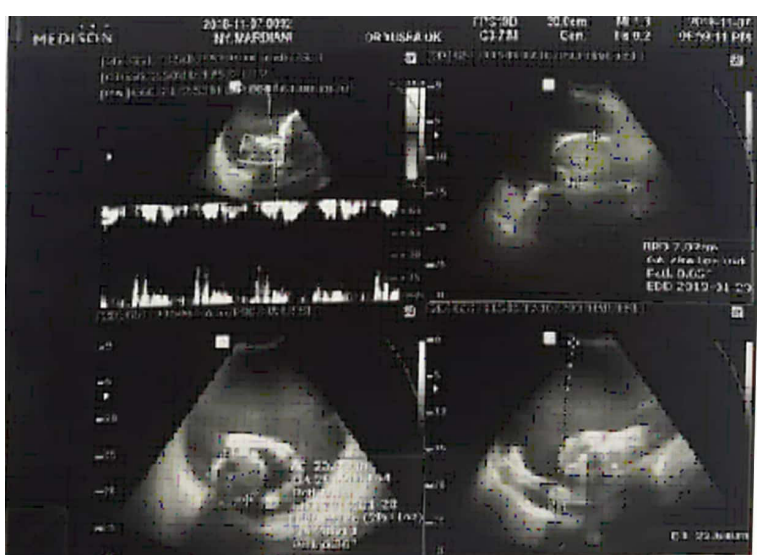

(a)

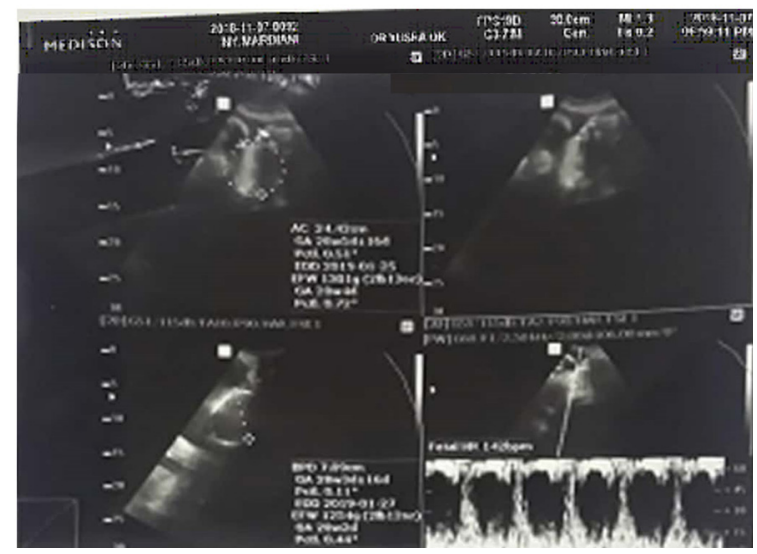

(b)

Gambar 1 (a) Gambaran USG biometri janin 1; BPD : 7,09 cm, AC: 24,42 cm, EFW: 1.301 gram, FHR: 142x/menit dan (b) biometri janin II; BPD: 7,02 cm, AC: 23,96 cm, EFW: 1.238 gram, FHR: 152x/ menit, SDP: $22,64 \mathrm{~cm}$ (kesan: polihidramnion); plasenta tertanam di korpus posterior maturase grade 2 . 
Hasil laboratorium didapatkan hemoglobin 11,2 gr\%, hematokrit 33\%, leukosit $10.480 / \mathrm{mm}^{3}$, trombosit $372.000 /$ $\mathrm{mm}^{3}$, prothrombin time (PT) 10,8", activated partial thromboplastin time (aPTT) 31,5"; gula darah sewaktu (GDS) $113 \mathrm{mg} / \mathrm{dl}$, ureum $20 \mathrm{mg} / \mathrm{dl}$, kreatinin $0,7 \mathrm{mg} / \mathrm{dl}$, kalsium 8,9 $\mathrm{mg} / \mathrm{dl}$, natrium $137 \mathrm{mmol} / \mathrm{dl}$, kalium 4,0 $\mathrm{mmol} / \mathrm{dl}$, klorida $110 \mathrm{mmol} / \mathrm{l}$, total protein $5,9 \mathrm{~g} / \mathrm{dl}$, albumin: $2,8 \mathrm{~g} / \mathrm{dl}$, globulin: $3,1 \mathrm{~g} / \mathrm{dl}$, SGOT: 16 u/l, SGPT: 13 u/l; LDH: 319 u/l.

Pasien mengeluhkan sesak di kehamilan 28 - 29 minggu; tindakan amnioreduksi dipertimbangkan untuk mengurangi sesak karena polihidramnion. Amnioreduksi dilakukan sebanyak dua kali dengan interval tiga hari pada usia kehamilan 28 - 29 minggu. Pada amnioreduksi pertama (9 November 2018) dan kedua (12 November 2018), cairan amnion berwarna jernih dikeluarkan sebanyak $\pm 2.000 \mathrm{cc}$ dan $\pm 900 \mathrm{cc}$.

Pada pasien ini dilakukan amniosentesis, sebagai pemeriksaan lanjutan berupa pengambilan sampel cairan amnion untuk dilakukan analisis kromosom dengan mengirimkannya ke Laboratorium Prodia yang nantinya akan dikirim ke Yayasan Genneka. Analisis kromosom dilakukan dengan teknik G-Banding dengan hasil 46, XX yang artinya jumlah kromosom 46 buah dengan komosom seks janin XX, tidak tampak kelainan stuktur yang major.

Pasien dipulangkan 1 hari setelah amnioreduksi kedua. Pasien dijadwalkan untuk kontrol kehamilan 7 hari kemudian. Pada kontrol kehamilan pertama diketahui dari pemeriksaan USG salah satu janin meninggal intra uterine fetal death (IUFD). Kematian salah satu janin dicurigai karena twin to twin transfusion syndrome.

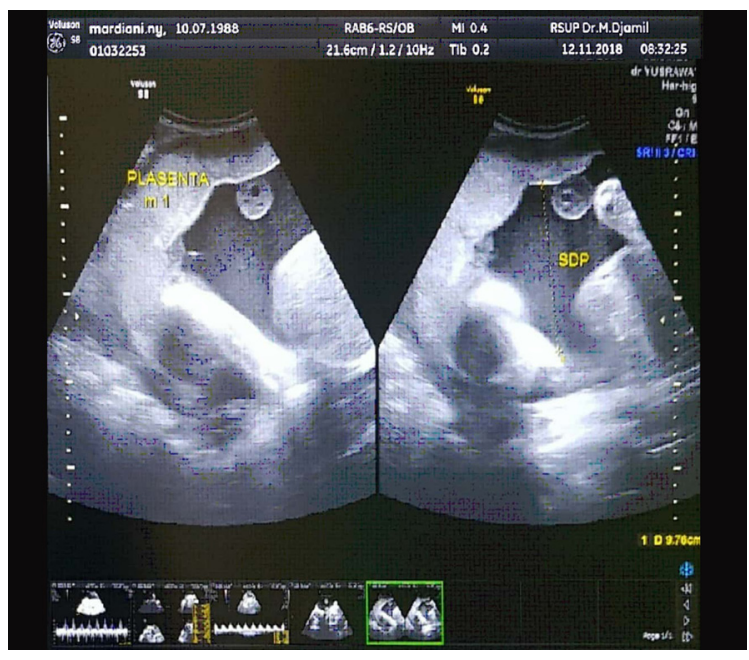

(a)

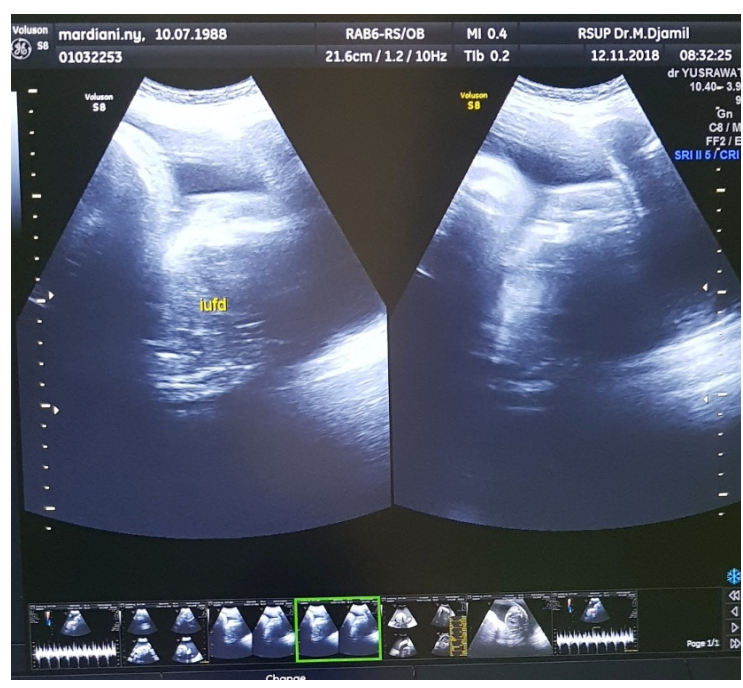

(b)

Gambar 2 Hasil USG setelah salah satu janin mengalami IUFD, kesan: gravid 30-31 minggu sesuai biometri, letak lintang, janin TTTS 1 hidup 1 meninggal, polihidramnion (a) Gambaran USG biometri janin 1; BPD : 7,78 cm, AC: $27,79 \mathrm{~cm}, \mathrm{HC}: 28,48 \mathrm{~cm}$, FL:6,41 cm, HL: 5,64 cm, EFW: 1.930 gram, SDP: 9,76, FHR: 145x/menit dan (b) FHR: negatif, Robert sign : positif; plasenta tertanam di korpus posterior maturase grade 2.

Kehamilan dipertahankan hingga aterm dengan follow up kadar fibrinogen darah 
pasien. Kadar fibrinogen dalam darah pasien adalah $510 \mathrm{mg} / \mathrm{dl}$.

Pada usia kehamilan 37 - 38 minggu dilakukan persalinan dengan section caesarea transperitoneal (SCTP) atas indikasi letak lintang. Bayi pertama berjenis kelamin perempuan, berat 1.800 gram, panjang badan $41 \mathrm{~cm}$, appearance, pulse, grimace, activity, respiration (APGAR) score 7/8. Bayi kedua berjenis kelamin perempuan, berat 500 gram, panjang badan $35 \mathrm{~cm}$, maserasi derajat III.

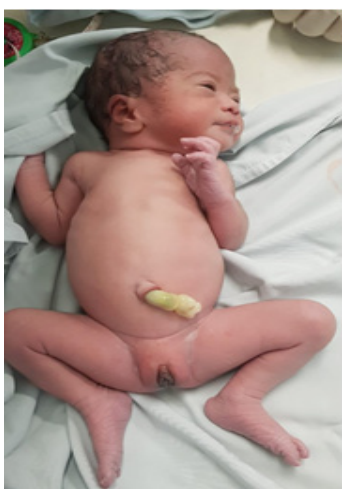

(a)

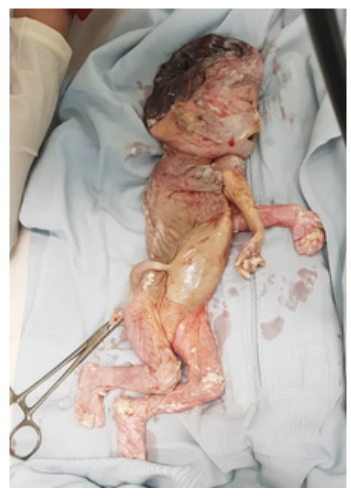

(b)
Gambar 3 Bayi dengan discordance twin (a) Foto bayi pertama (IUGR); (b) foto bayi kedua (IUFD)

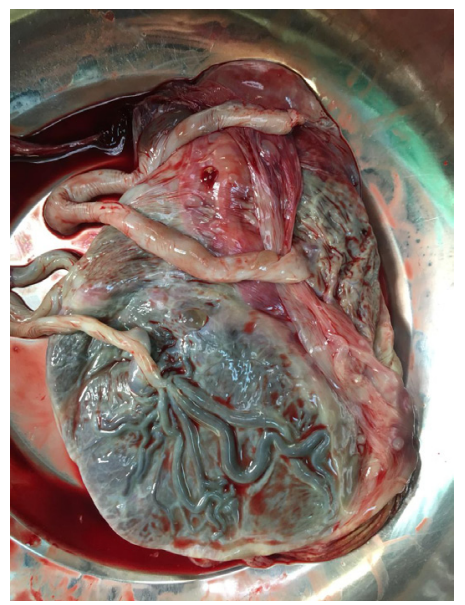

Gambar 4 Foto monokorion diamniotik pada kasus ini.

Setelah dilakukan tindakan sectio caesarea didapatkan salah satu bayi mengalami intra uterine growth restriction
(IUGR) dan bayi lainnya mengalami IUFD. Intra uterine growth restriction dan kematian janin di dalam rahim/IUFD pada kasus ini terjadi akibat twin to twin transfusion syndrome.

\section{Hasil Dan Diskusi}

Telah dilaporkan suatu kasus twin to twin trasnfusion syndrome. Diagnosis ditegakkan dengan pemeriksaan USG antenatal yang cermat dan berulang.

Mekanisme perkembangan dari kembar monozigot belum sepenuhnya bisa dijelaskan. ${ }^{7,8}$ Keadaan akhir dari kembar monozigot tergantung kepada proses pembelahan. Jika zigot membelah dalam 72 jam pertama setelah pembuahan, dua embrio, dua amnion dan dua korion akan berkembang, dan sebuah kehamilan kembar dikorionik diamniotik akan terjadi. Dua plasenta yang berbeda atau satu plasenta tunggal dapat terbentuk. Jika pembelahan tejadi antara hari keempat dan kedelapan, sebuah kehamilan kembar monokorin diamniotik dapat terjadi. ${ }^{9-11}$

Pasien datang pada kehamilan trimester ketiga dengan diagnosis awal $\mathrm{G}_{2} \mathrm{P}_{1} \mathrm{~A}_{0} \mathrm{H}_{1}$ gravid preterm 27 - 28 minggu dengan TTTS. Klasifikasi TTTS adalah ${ }^{11,12}$ :

Dari hasil USG awal di RSUP Dr. M. Djamil didapatkan kesan gravid 28 - 29 minggu sesuai biometri dengan TTTS + letak lintang + polihidramnion. Twin to twin trasnfusion syndrome (baik pada stadium satu) merupakan kondisi yang dapat tetap stabil dan juga progresif (10-30\% kasus). Progresivitas dapat berkembang dalam hitungan hari hingga minggu. Hal ini menyebabkan pasien wajib dipantau secara ketat. ${ }^{13}$

Beberapa hari dalam rawatan, pasien mengeluhkan sesak sehingga direncanakan amnioreduksi. Amnioreduksi dapat dilakukan pada usia kehamilan $>14$ minggu. Amnioreduksi dapat mengurangi tekanan 
Tabel 1 Klasifikasi Twin to Twin Transfusion Syndrome

\begin{tabular}{|c|c|c|}
\hline Stage & Temuan Ultrasound & Kategori Kriteria \\
\hline 1 & $\begin{array}{l}\text { Maximum vertical pocket (MVP) } \\
\text { dari cairan amnion }\end{array}$ & $\begin{array}{l}\text { Maximum vertical pocket (MVP) }<2 \mathrm{~cm} \text { pada kantung donor, } \\
\text { MVP }>8 \mathrm{~cm} \text { pada kantung resipien }\end{array}$ \\
\hline 2 & Kandung kemih fetus & $\begin{array}{l}\text { Tidak tervisualisasikan kandung kemih fetus pada donor se- } \\
\text { lama lebih dari } 60 \text { menit observasi }\end{array}$ \\
\hline 3 & $\begin{array}{l}\text { Arteri umbilikal, ductus venosus, } \\
\text { dan gelombang doppler vena um- } \\
\text { bilical }\end{array}$ & $\begin{array}{l}\text { Tidak ada atau kelainan diastolik arteri umbilikal, ductus ve- } \\
\text { nosus, atau vena umbilikal pada pemeriksaan Doppler }\end{array}$ \\
\hline 4 & Fetal hydrops/asites & Hydrops/ asites pada salah satu atau kedua kembar \\
\hline 5 & Tidak ada aktivitas kardiak fetal & Kematian salah satu atau kedua kembar \\
\hline
\end{tabular}

intraamnion dan intravaskular plasenta, memfasilitasi aliran darah plasenta dan/ atau dapat mengurangi insiden kelahiran prematur karena polihidramnion. Jika amnioreduksi dilakukan pada kehamilan $>26$ minggu, biasanya pada kasus maternal respiratory distress atau kontraksi preterm yang disebabkan oleh polihidramnion. ${ }^{14}$ Amnioreduksi serial sering dilakukan (interval 48-72 jam), ${ }^{15}$ prosedur ini memiliki komplikasi seperti pecah ketuban dini, persalinan prematur, abrupsi, infeksi dan kematian janin. ${ }^{16}$ Amnioreduksi meningkatkan survival $60-65 \%{ }^{17,18}$ dan survival rate pasien TTTS stadium I menjadi $77 \% .{ }^{19}$ Ini menjadi dasar pemilihan tindakan amnioreduksi pada kasus ini.

Pada amnioreduksi pertama, dikeluarkan cairan amnion jernih sebanyak $\pm 2.000 \mathrm{cc}$. Tiga hari kemudian dilakukan amnioreduksi kedua dan dikeluarkan cairan amnion jernih sebanyak \pm 900 cc. Pasien dipulangkan satu hari setelah amnioreduksi dan akan kontrol kembali 7 hari kemudian. Salah satu janin diketahui mengalama IUFD saat pasien kontrol kembali (setelah pasien dipulangkan).

Analisis kromosom yang dilakukan dengan teknik G-Banding memberikan hasil 46XX, artinya jumlah kromosom 46 buah dengan komosom seks janin XX dan tidak tampak kelainan stuktur yang major.

Twin to twin transfusion syndrome bukan merupakan faktor yang diturunkan/genetik atau disebabkan oleh sesuatu yang dilakukan oleh ibu atau ayah..$^{2-4}$

Belum ada pernyataan waktu kehamilan optimal untuk persalinan pada kehamilan TTTS. Hal ini tergantung kepada beberapa faktor, seperti stadium dan severitas, progresivitas, efek intervensi (jika ada) dan pemeriksaan antenatal lainnya. Rekomendasi untuk waktu persalinan TTTS ada bermacammacam, ada yang merekomendasikan pada usia kehamilan 32 - 34 minggu, dan ada juga yang merekomendasikan pada usia kehamilan 34 - 37 minggu (biasanya pada kasus dengan TTTS stadium 1 dan 2 atau pada kasus dengan follow up yang ketat). Kadar fibrinogen darah merupakan salah satu pemeriksaan yang dipantau (diharapkan nilai tidak di bawah nilai normal). ${ }^{15,2}$

Salah satu komplikasi yang ditakutkan dari persalinan prematur adalah meningkatnya risiko gangguan perkembangan neurologi. ${ }^{20,21}$ Pada kasus adanya kematian salah satu janin di dalam rahim, maka akan menigkatkan 10\% risiko kematian dari janin lainnya dan 10 $30 \%$ risiko komplikasi neurologi. ${ }^{22}$ Dapat disimpulkan ada bermacam faktor yang perlu dipertimbangkan dalam menentukan waktu persalinan yaitu stadium, progresivitas, respon terhadap terapi, pertumbuhan fetal, dan hasil dari follow up selama antenatal. Berdasarkan hal tersebut menunda persalinan hingga aterm menjadi pilihan yang tepat meskipun sudah dilakukan intervensi selama 
kehamilan untuk mengurangi resiko gangguan neurologis. ${ }^{21}$ Pada penanganan kasus TTTS ini dilakukan perencanaan partus seaterm mungkin dengan pengawasan yang ketat. Setelah kematian salah satu janin pemantauan dengan ultrasonografi dan laboratorium tetap dilakukan.

Dari hasil laboratorium dapat disimpulkan tedapat peningkatan fibrinogen $(510 \mathrm{mg} /$ dl), sedangkan gambaran ultrasonografi disimpulkan gravid 30 - 31 minggu sesuai biometri + TTTS dengan janin 1 hidup 1 meninggal+letak lintang+polihidramnion.

Persalinan secara sectio caesarea atas indikasi letak lintang; dilakukan pada usia kehamilan 37 - 38 minggu. Bayi pertama berjenis kelamin perempuan, berat 1.800 gram, panjang badan $41 \mathrm{~cm}$, appearance, pulse, grimace, activity, respiration (APGAR) score 7/8. Bayi kedua berjenis kelamin perempuan, berat 500 gram, panjang badan $35 \mathrm{~cm}$, maserasi derajat III. Setelah dilakukan tindakan sectio caesarea didapatkan salah satu bayi mengalami IUGR dan bayi lainnya mengalami IUFD. Intra uterine growth restriction dan kematian janin di dalam rahim/ IUFD pada salah kasus ini terjadi akibat twin to twin transfusion syndrome. ${ }^{1}$

\section{Kesimpulan}

Twin to twin transfusion syndrome merupakan suatu komplikasi dari kehamilan multipel monokorion yang berisiko tinggi menyebabkan kematian fetal/neonatus. Diperlukan pemeriksaan prenatal yang cermat dan berulang dalam penegakan diagnosis dan manajemen TTTS karena kemungkinan progresifitasnya. Pada bayi yang bertahan hidup juga diperlukan pemeriksaan fungsi organ lebih lanjut. Kasus yang dilaporkan ini merupakan kasus TTTS berdasarkan temuan USG prenatal.

\section{Daftar Pustaka}

1. Nora H, Twin-twin transfusion syndrome. Jurnal Kedokteran Syiah Kuala. 2013; 13(2): 86-95.

2. Quintero RA, Morales WJ, Allen MH, Bornick PW, Johnson PK, Kruger M, Staging of twin-twin transfusion syndrome. J.Perinatol. 1999; 19: 550-5.

3. Taylor MJ, Govender L, Jolly M, Wee L, Fisk NM. Validation of the Quintero staging system for twin-twin transfusion syndrome. Obstet Gynecol. 2002; 100: 1257-65.

4. Nicholas dan Galea, Twin-twin transfusion - As good as it gets?. New England medical Journal. 2004; 14(7), available at http:// www.nejm.org .

5. Caroline F, Mark D, Khalid S. Contemporary treatments for twintwin transfusion syndrom. Am $J$ Obstet Gynecol. 2005; 105:1469-77

6. Liesbeth L, Schoubroecka DV, Grataco E, Wittersa I, Timmermana D, Depresta J. Monochorionic diamniotic twins: complications and management options. Am J Obstet Gynecol. 2015:177-9.

7. Rekha B, Ling Y, Shaheen A, Stuart W. Outcome of twin pregnancies complicated by single intrauterine death in relation to vascular anatomy of the monochorionic placenta. American Journal of Obstetrics and Gynecology. 1999; 14(8): 2124-30.

8. Romaine R, Masami Y, Yves V. Selective feticide in complicated monochorionic twin pregnancies using ultrasound guided bipolar cordcoagulation. BJOG. 2005; 112(10): 1344-48.

9. Twin to twin transfusion syndrome [editorial]. BMJ. 2007; 316: 1581-6.

10. Cunningham FG. Mulifetal pregnancy. William Obstetrics Edisi ke-23. New York Mc Graw Hill. 2010; 765-809.

11. Dev K, Menin. A retrospective study of the accuracy of sonographic chorionicity determination in twin pregnancies. 
Australian Journal of Obstetrics. 2006; 3(8): 259-61.

12. Society for Maternal-Fetal Medicine (SMFM) dan Simpson L.L., Twin to twin transfusion syndrome. American Journal of Obstetrics and Gynecology (2013) 208(1): 3-18.

13. O’Donoghue K, Cartwright E, Galea P, Fisk NM. Stage I twin-twin transfusion syndrome: rates of progression and regression in relation to outcome. Ultrasound Obstet Gynecol. 2007; 30: 958-64.

14. Chalouhi GE, Stirnemann JJ, Salomon LJ, Essaoui M, Quibel T, Ville Y. Specific complications of monochorionic twin pregnancies: twin-twin transfusion syndrome and twin reversed arterial perfusion sequence. Semin Fetal Neonatal Med 2010;15:349-56.

15. Moise KJ Jr, Dorman K, Lamvu G, et al. A randomized trial of amnioreduction versus septostomy in the treatment of twin-twin transfusion syndrome. $\mathrm{Am} \mathrm{J}$ Obstet Gynecol. 2005;193:701-7.

16. Roberts D, Gates S, Kilby M, Neilson JP. Interventions for twin-twin transfusion syndrome: a Cochrane review. Ultrasound Obstet Gynecol. 2008;31:701-11.

17. Dickinson JE, Evans SF. Obstetric and perinatal outcomes from the Australian and New Zealand twin-twin transfusion syndrome registry. Am J Obstet Gynecol. 2000;182:706-12.
18. Mari G, Roberts A, Detti L, et al. Perinatal morbidity and mortality rates in severe twin-twin transfusion syndrome: results of the international amnioreduction registry. Am J Obstet Gynecol. 2001;185:708-15.

19. Rossi C, D'Addario V. Survival outcomes of twin-twin transfusion syndrome in stage I: a sys-tematic review of the literature. Am J Perinatol. 2012; 6(26) [epub ahead of print].

20. Senat MV, Deprest J, Boulvain M, Paupe A, Winer N, Ville Y. Endoscopic laser surgery versus serial amnioreduction for severe twin-to-twin transfusion syndrome. N Engl J Med. 2004 ;351:136-44.

21. Lopriore E, Ortibus E, Acosta-Rojas R, et al. Risk factors for neurodevelopment impairment in twin-twin transfusion syndrome treated with fetoscopic laser surgery. Obstet Gynecol. 2009; 113:361-6.

22. Banek CS, Hecher K, Hackeloer BJ, Bartmann P. Long-term neurodevelopmental outcome after intrauterine laser treatment for severe twin-twin transfusion syndrome. $\mathrm{Am} \mathrm{J}$ Obstet Gynecol. 2003;188:876-80. 